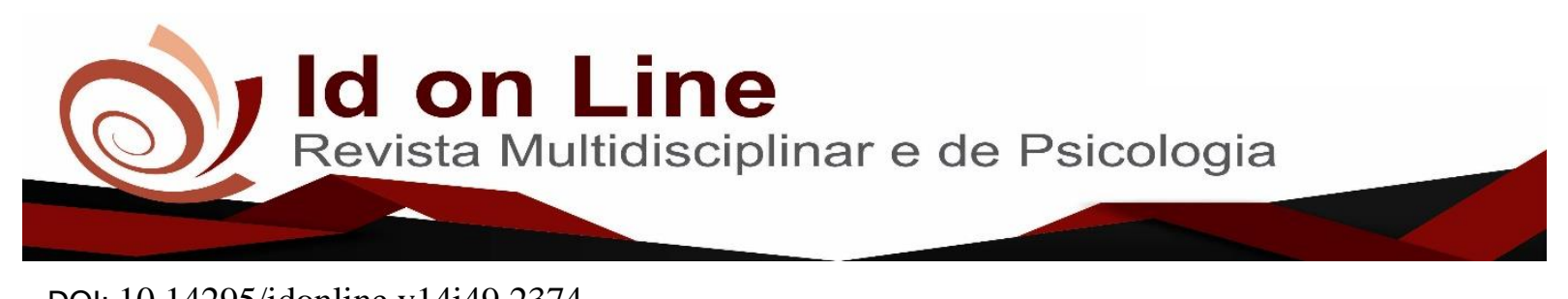

DOI: 10.14295/idonline.v14i49.2374

Artigo

\title{
Relativização do Princípio da Imutabilidade do Nome Civil
}

Natasha Santana Sloniewski Galvão ${ }^{1}$

Resumo: O presente trabalho tem como base as possibilidades de modificação do nome civil, mais especificamente o prenome (pré-apelido da família), sem que haja necessidade de acionar o judiciário e passado o prazo estipulado pelo código civil de 2002, respeitando a segurança jurídica do ato, tendo como norteador o princípio da dignidade da pessoa humana, de forma que haja uma adequação jurídica conforme o desenvolvimento e avanço da sociedade humana. $\mathrm{O}$ trabalho busca uma análise prévia relacionada à relativização do princípio da imutabilidade do nome civil, tendo por base jurisprudências dos tribunais nacionais, e análise dos entendimentos doutrinários relacionados ao tema proposto.

Palavras-chave: Prenome; Alteração; Imutabilidade.

\section{Relativization of the Principle of Immutability of the Civil Name}

\begin{abstract}
The present work is based on the possibilities of modifying the civil name, more specifically the first name (family surname), without the need to sue the judiciary and after the deadline stipulated by the civil code of 2002, respecting security of the act, having as its guiding principle the dignity of the human person, so that there is a legal adequacy according to the development and advancement of human society. The work seeks a previous analysis related to the relativization of the principle of immutability of the civil name, based on the jurisprudence of the national courts, and an analysis of the doctrinal understandings related to the proposed theme.
\end{abstract}

Keywords: First name; Alteration; Immutability

\section{Introdução}

Este trabalho tem o intuito de demonstrar que o judiciário tem a necessidade de acompanhar o desenvolvimento e a evolução da sociedade humana, de modo que a relativização do princípio da imutabilidade do prenome, venha trazer celeridade a quem busca solucionar o problema referente ao tema, sem que haja necessidade de acionar o jurídico, fazendo assim com que haja uma diminuição de processos nos tribunais.

\footnotetext{
${ }^{1}$ Graduação em Direito pela Universidade Estácio. Pós-Graduação em Direito Internacional pelo Instituto Brasileiro de Formação - IBF. natasha.sloniewski@gmail.com.
} 
O prenome, ou, nome civil, é o nome de batismo de um indivíduo, nome que antecede o nome da família (sobrenome). O prenome será o nome inserido na certidão de nascimento. $\mathrm{O}$ prenome tem grande importância na vida de uma pessoa, pois é através dele que ocorre uma diferenciação em seu seio familiar, bem como, é através dele que o indivíduo é reconhecido e diferenciado em sociedade.

A escolha do nome é feita através dos pais do indivíduo e deve estar em acordo com a legislação brasileira, de modo que não cause vergonha, não cause estranheza absurda, não cause mal estar para a pessoa que será batizada.

Para isto, temos artigos específicos no nosso código civil, e ainda, amparo na lei 6015/73, que trata da postura dos oficiais de cartório civil, da permissão para se recusarem a registrar o nome escolhido diante da possibilidade de expor o indivíduo ao ridículo, que seja vexatório ou cause qualquer situação desconfortável.

Em tese, a lei brasileira preza pela imutabilidade do nome civil, sendo permitida a mudança apenas em caso de erro gráfico, exposição do portador ao ridículo com o advento da maioridade civil ou inclusão de apelido público notório, conforme prevê a lei n. 9.708/98, e considerando o princípio da dignidade da pessoa humana, respeitando a vontade e a necessidade de cada um.

O fato é que com a evolução da sociedade, deve haver uma adequação do judiciário com a finalidade de atender as necessidades pessoais de cada indivíduo, buscando sempre facilitar e ser alcançável pela pessoa que busca sanar seu problema, sem que haja prejuízo da segurança jurídica.

Atualmente, conforme Lei n. 9.708/98, o art. 58 “caput” da Lei dos Registros Públicos foi derrogado, passando a vigorar com a seguinte redação: “O prenome será definitivo, admitindo-se, todavia, a sua substituição por apelidos públicos notórios”, porém, temos o caso dos transexuais, que após a transição de gênero, desejam reconhecimento social através do nome que escolheram para acompanhar essa transição, o que torna inviável para um ser humano que se declara do sexo feminino ser chamado por um prenome masculino.

O que o presente trabalho busca, é a adequação jurídica com a evolução social, tendo em vista que atualmente, o indivíduo que busca modificar seu prenome encontra grande dificuldade jurídica, bem como necessita de um grande gasto financeiro e emocional, uma vez que ao iniciar o processo de mudança de nome, não há qualquer garantia de deferimento por parte da justiça, demonstrando a necessidade de uma justiça mais célere e menos burocrática 
para sanar tal problema. Por isso há uma grande necessidade de flexibilizar a imutabilidade do prenome, para que não haja um congestionamento jurídico em busca de solução para o problema apresentado e para que a pessoa que busca essa solução sofra o menos possível, tendo preservada a sua vontade e a sua dignidade, contando com o respaldo de diversas decisões de tribunais brasileiros.

\section{Do Direito ao Nome Civil}

\section{Do Direito ao Prenome}

Ao nascer, o indivíduo adquire personalidade jurídica, logo, adquire também os direitos a ela atrelados, inserindo-se neste contexto, o nome.

O nome está diretamente ligado à identidade de uma pessoa, e por estar ligado aos direitos da personalidade, torna-se inalienável, irrenunciável e intransmissível.

Conforme dispõe o artigo 16 do código civil, "Toda pessoa tem direito ao nome, nele compreendidos o prenome e o sobrenome.", de modo que o nome é parte da personalidade do indivíduo, gozando de proteção legal.

É através do prenome que a pessoa é reconhecida em sociedade e em seu seio familiar, difirenciando-a dos demais, motivo pelo qual, por ser de grande exposição, não deverá ser vexatório, expor ao ridículo ou causar estranheza e vergonha.

De acordo com o artigo 11 do código civil de 2002, "Com exceção dos casos previstos em lei, os direitos da personalidade são intransmissíveis e irrenunciáveis, não podendo o seu exercício sofrer limitação voluntária.”, deste modo, o direito ao nome está diretamente ligado aos direitos da personalidade, uma vez que o nome é atrelado ao indivíduo e faz parte de sua identidade, gozando de toda proteção legal, uma vez que "Os direitos da personalidade são os que resguardam a dignidade humana.", conforme o entendimento de Silvio de Salvo Venosa ${ }^{1}$.

\section{Função e Definição}

O Prenome é o nome próprio do indivíduo e tem como função a diferenciação deste no meio familiar e social, podendo ser simples, ex: Camila, ou composto, ex: Maria Aparecida. 
O Sobrenome acompanha o prenome do indivíduo e está ligado a sua ascendência, adquirido através da filiação, de modo que se transmite por sucessão, podendo ser utilizado o sobrenome da mãe, do pai ou de ambos.

A pessoa também pode ser identificada através do:

Agnome que é utilizado para diferenciar dos seus homônimos, como, Filho, Neto, Junior, por exemplo, José da Silva Filho;

Cognome que é o apelido pelo qual a pessoa fica conhecida na sociedade, como por exemplo, Zeca - referente ao nome José Carlos, Cadu - referente ao nome Carlos Eduardo, entre outros;

Axiônimo que se utiliza para reverências e formas respeitosas de tratamento como Vossa Excelência, Doutor, etc.

Conforme prevê o artigo 58 da lei $6015 / 73^{2}$, que teve sua redação alterada pela Lei ${ }^{\circ}$ 9.708, de 1998, “O prenome será definitivo, admitindo-se, todavia, a sua substituição por apelidos públicos notórios", sendo o caso de artistas que tem seu apelido atrelado a sua profissão e através destes são reconhecidos, como por exemplo, a cantora Larissa de Macedo Machado, conhecida por seu apelido Anitta. Desta forma, o apelido público goza da proteção legal atribuída ao nome civil, uma vez que passou a fazer parte da identidade do indivíduo.

De acordo com José Roberto Neves Amorim³

\begin{abstract}
Classificado entre os direitos da personalidade, o nome é inerente à própria pessoa que, como já dito, a individualiza em si mesma e nas suas ações. O ordenamento jurídico tutela a identidade pessoal, protegendo-a de possíveis danos morais e materiais. O nome também tem sua importância aumentada à medida que a pessoa tenha reputação conhecida por distinção na sociedade.
\end{abstract}

Desta forma, o registro do nascimento da pessoa em cartório é de suma importância, em razão da necessidade do reconhecimento social por seu nome e sobrenome.

\title{
O Registro Civil das Pessoas Naturais e sua Importância
}

É através do registro civil que o indivíduo consegue comprovar a sua existência, e ainda os atos de sua vida civil, como a obtenção da maioridade, nascimento, morte e estado civil.

\footnotetext{
2 Art. 58 da Lei 6017/1973 O prenome será definitivo, admitindo-se, todavia, a sua substituição por apelidos públicos notórios. ${ }^{3}$ AMORIM, José Roberto Neves. Direito ao nome da pessoa física. São Paulo: Saraiva, 2003 - p.73. 
No que se refere ao registro do nome civil, é regulamentado pela lei 6.015/73, que em seu artigo 54, informa o que deve conter no registro de nascimento, sendo o prenome, sobrenome, dia, mês e ano, local de nascimento, sexo e nome dos pais.

Em regra, o registro do nome civil é imutável, visando garantir a segurança jurídica dos atos civis da pessoa, porém, a lei de registros públicos traz suas exceções sendo estas no primeiro ano após o advento da maioridade civil por qualquer motivo, em caso de substituição por apelido público notório, proteção a testemunhas e ainda, erros de grafia, após o devido processo judicial para sua concretização.

Será vedado o registro de prenome vexatório, podendo o oficial de cartório se negar a efetuar o registro em razão da escolha de prenome que cause vergonha e estranheza, conforme prevê o parágrafo único do artigo 55 da lei 6015/73. Cabe ressaltar que a definição de vexatório é relativa, uma vez que aquilo que causa repúdio e vergonha para uns, não significa vergonha e repúdio para outras pessoas. Deve haver bom senso de ambos os lados, seja dos pais ou do oficial do cartório, no momento da escolha e registro do nome civil.

Caso haja insistência dos pais para que o registro seja realizado com nome incomum ou vexatório, o oficial deve remeter a situação ao juiz competente sob forma de dúvida, conforme entendimento de Silvio de Salvo Venosa ${ }^{4}$ :

\footnotetext{
Essa regra também se aplica aos apelidos, agora permitidos como prenomes pela lei. $\mathrm{O}$ oficial do registro tem o dever de recusar-se a efetuar registro nessas condições; e, no caso de insistência do registrante, deve submeter, sob forma de dúvida, o caso ao juiz competente. Se ocorrer, porém, o registro de nome ridículo, mesmo com esse dever imposto ao oficial, permite-se a alteração do prenome.
}

Contudo, não há necessidade de esperar o advento da maioridade para que a modificação do prenome seja realizada, uma vez que o menor assistido ou devidamente representado, desde que preenchidos os requisitos para o feito, possui legitimidade, de acordo com Silvio de Salvo Venosa, "primeiramente, não é necessário que o menor espere a maioridade para alterar um nome ridículo, o que fará assistido ou representado, se for o caso.”.

No que se refere ao sobrenome, caberá retificação para inclusão do sobrenome materno e ainda, a inclusão do sobrenome paterno desde que haja autorização e manifestação expressa em juízo. 


\section{Da Imutabilidade do Nome Civil e suas Exceções}

\section{Do Princípio da Imutabilidade}

A imutabilidade se dá em razão do iluminismo oitocentista, no qual visava à preservação da segurança jurídica, ainda que direitos fundamentais fossem desrespeitados. A inalterabilidade do nome civil com intuito de priorizar relações econômicas se dá em razão da redação originária do artigo 58 da lei 6015/73.

Em razão do desenvolvimento histórico e social, e ainda, o firmamento da dignidade da pessoa humana e nova visão sobre os valores tidos por fundamentais imateriais, houve necessidade de adequação da legislação referente ao nome civil, de modo que tornou este protegido, porém, visando a proteção dos interesses de seu titular e não o interesse econômico e social de terceiros.

No passado, o nome tinha grande relevância para identificação do caráter do indivíduo, de modo que este se modificava no decorrer da vida conforme seu caráter interferisse em suas posturas, porém, em razão da evolução da sociedade, o nome civil passou ser atrelado a personalidade da pessoa, visando identifica-la, garantir seu lastro histórico, social, familiar e cultural.

Embora, por força da lei 9.708/98 o nome ainda goze de definitividade, no que se refere ao prenome, passou a ser definitivo, porém se admitindo algumas situações de modificação, se estendendo a relativização da imutabilidade ao sobrenome.

\section{Das Exceções ao Princípio da Imutabilidade}

Em regra, aplica-se a inalterabilidade do nome civil, porém, é importante ressaltar que o legislador foi cauteloso em permitir que dentro da imutabilidade do prenome, existem possibilidades de modificá-lo, pois, se em regra o direito ao nome é fundamental ao ser humano, a dignidade da pessoa humana é visivelmente predominante.

A imutabilidade do nome civil se dá em razão da primeira parte do artigo 58 da lei $\mathrm{n}^{\circ}$ 6015/73, sendo admitidas por lei, algumas alterações.

Desta forma, são as hipóteses de modificação do prenome civil: 
ADOÇÃO: Conforme prevê o Estatuto da criança e do Adolescente, “ Art 47 - O vínculo da adoção constitui-se por sentença judicial, que será inscrita no registro civil mediante mandado do qual não se fornecerá certidão" e "Art 47 § 5ำ - A sentença conferirá ao adotado o nome do adotante e, a pedido de qualquer deles, poderá determinar a modificação do prenome."

Deste modo, após a conclusão do processo de adoção, transferindo-se a guarda definitiva do menor, o registro inicial será desconsiderado, podendo ser fornecido apenas por ordem judicial.

Haverá um novo registro do menor adotado, onde este passará a utilizar o sobrenome dos pais adotivos, bem como se incluirá a ascendência, ou seja, avós, pais dos adotantes.

A adoção é ainda, hipótese de modificação do prenome (nome civil) do menor adotado, de modo que esta modificação deverá ser solicitada juntamente ao pedido de adoção.

Cabe ressaltar dentro desta hipótese, o reconhecimento de paternidade, sendo possível a inclusão do sobrenome do pai, e, ainda, a modificação em razão da filiação socioafetiva, aquela nascida com a convivência, que prevalecerá sobre o vínculo biológico.

Casamento: O código civil de 2002, em seu artigo 1.565, § $1^{\text {o5 }}$, permite aos nubentes, a inclusão do sobrenome do cônjuge, com o advento do casamento.

A inclusão do sobrenome do cônjuge será feita por declaração pessoal e expressa no cartório, no momento da habilitação do casamento, não havendo necessidade de autorização judicial, sendo defesa ao marido ou esposa.

Em razão do avanço social, por força do artigo 226, § $3^{\circ}$ da Constituição Federal, com o surgimento da possibilidade de união estável sendo esta equiparada ao casamento, também é permitido que haja inclusão do sobrenome do companheiro ou companheira, porém, haverá necessidade de autorização judicial para que seja concretizada a alteração, através de um processo em que deverá ser comprovada a existência da união estável, o manifesto de interesse em alteração do sobrenome, e ainda, a concordância do parceiro, desde que não tenha impedimento legal para o casamento.

Se por um lado, com a união do casal é permitido adquirir o sobrenome do outro, o divórcio, ruptura do vínculo judicial do casamento, também se inclui na hipótese de modificação do

\footnotetext{
5 Art. 1.565 do Código Civil de 2002- Pelo casamento, homem e mulher assumem mutuamente a condição de consortes, companheiros e responsáveis pelos encargos da família.

Parágrafo único. Os oficiais do registro civil não registrarão prenomes suscetíveis de expor ao ridículo os seus portadores. Quando os pais não se conformarem com a recusa do oficial, este submeterá por escrito o caso, independente da cobrança de quaisquer emolumentos, à decisão do Juiz competente.
} 
nome, uma vez que ao declarar no documento de formalização da separação, poderá o excônjuge excluir o sobrenome do ex-companheiro.

Cabe ressaltar que o fim do vínculo matrimonial não acarreta na obrigação de exclusão do sobrenome do ex-conjuge, de modo que, caso a pessoa tenha interesse por qualquer motivo, em manter o sobrenome adquirido, e o outro autorize, poderá permanecer sem alterar o nome. Neste caso, temos como exemplo o cônjuge que fica conhecido profissionalmente através do sobrenome do outro.

Proteção de testemunhas: Neste caso, o parágrafo único do artigo 58 da lei de registros públicos é clara ao informar que "A substituição do prenome será ainda admitida em razão de fundada coação ou ameaça decorrente da colaboração com a apuração de crime, por determinação, em sentença, de juiz competente, ouvindo o Ministério Público.", de modo que o legislador visou a proteção das vítimas e testemunhas de crimes e que sofrem ameaças.

Deverá ser requerido ao juiz competente, com oitiva do Ministério Público, podendo a modificação do registro ser revertida em razão da cessação da coação ou ameaça a vítima, sendo o procedimento submetido ao rito sumário, correndo em segredo de justiça.

Erro de grafia: Neste caso, o erro é praticado pelo Cartório do Registro Civil, podendo o interessado, seu representante legal ou procurador, requerer diretamente ao cartório em que foi emitido o documento, a correção, e o próprio cartório remeterá o requerimento ao Poder Judiciário e Ministério Público, solicitando autorização para realizar a devida correção, não podendo o Oficial de cartório realizar a retificação de oficio.

Com a autorização do poder judiciário, o pedido retorna ao cartório para que este realize a correção necessária. Porém, há de se destacar os casos em que o erro não é causado pelo Cartório, como por exemplo, quando o cartório emite documento baseando-se em documento oficial. Nestes casos, a retificação somente poderá ser realizada por processo judicial, pelo próprio interessado, não havendo intervenção do Cartório que produziu o documento.

O interessado deverá narrar os fatos, explicar a situação no processo judicial e indicar onde deverá ser realizada a correção, e após apreciado pelo juiz, será remetido ao Ministério Público para que este informe sua opinião, e somente após a concordância do Ministério Público, o processo retornará ao Juiz, que somente após a conclusão de que tal retificação não prejudique a segurança jurídica dos atos praticados por esta pessoa à terceiros, dará por autorizada a correção. 
Após a autorização da alteração do prenome, ficando comprovado que não há qualquer oposição ao ato, será expedido um mandado ao cartório e o interessado, deverá dirigir-se até o local que expediu o documento, para que seja realizada a correção.

Homonímia: Trata-se dos casos que existem duas ou mais pessoas possuidoras do mesmo nome e sobrenome, e em decorrência disto, acarreta confusões cotidianas, como por exemplo, a confusão de CPF em razão de nomes iguais.

Desta forma, a jurisprudência é favorável para alteração do sobrenome, ou ainda, acréscimo de mais um sobrenome para que haja diferenciação.

Naturalização: Em razão da lei $n^{\circ} 6.815$ de 1980, referente a Naturalização de estrangeiros, é admitida a mudança de prenome e sobrenome estrangeiro, para que ocorra facilitação de pronuncia e convivência com brasileiros, de forma que a tradução substitui o nome e sobrenome, porém, seu significado é mantido, havendo adequação a gramática brasileira. De acordo com Maria Helena Diniz: ${ }^{6}$

\begin{abstract}
A escolha pela simples adaptação à língua portuguesa parece-nos mais complicado, posto que passível de estabelecer confusão de identidade entre os parentes com prenomes iguais e, principalmente, com relação ao nome de família, posto que, se alguns membros de uma mesma família estrangeira ao se naturalizarem brasileiro optem pela tradução para a língua portuguesa e outros pela simples adaptação, que poderá ser feita de formas variadas, com certeza dificultará, no futuro, a identificação do parentesco entre eles e eles e seus descendentes, se não gerar uma confusão nesta relação.
\end{abstract}

Desta maneira, é mais adequado que o estrangeiro que naturalizar-se brasileiro, escolha pela tradução de seu nome se não desejar continuar utilizando o nome originário, em conformidade com o Artigo 115, $\S 3^{\circ}$ do Estatuto do Estrangeiro.

NOME VEXATÓRIO: De acordo com os direitos da pessoa humana, sendo estes o direito a vida, a liberdade física, a liberdade intelectual, ao corpo e imagem e ainda, a honra, sendo estes imprescritíveis, irrenunciáveis, intransmissíveis e inalienáveis, a tutela civilista é mínima perante o princípio da dignidade da pessoa humana, de forma que, dentre os direitos da personalidade, encontra-se o direito ao nome, conforme o artigo 16 do código civil ${ }^{7}$.

Em razão do princípio da dignidade da pessoa humana, soberano à segurança jurídica das ações do ser humano, aquele que possui prenome vexatório, que o exponha ao ridículo, pode, ao adquirir maioridade civil solicitar a alteração do nome civil. É necessário que haja bom senso no momento de escolher o nome de uma pessoa, uma vez que, um nome que cause constrangimento pode acarretar diversos problemas de cunho psicológico e social na pessoa.

\footnotetext{
${ }^{6}$ DINIZ, Maria Helena. Curso de Direito - V. 5.18. ecL. De acordo com o novo Código Civil. São Paulo: Saraiva, 2002.

${ }^{7}$ Art. 16 - Código Civil de 2002 - Toda pessoa tem direito ao nome, nele compreendidos o prenome e o sobrenome. 
A lei 6015 de 1973, em seu artigo 55 $5^{8}$, parágrafo único, assegura aos oficiais de cartório o direito de recusa em registrar prenome vexatório, devendo o mesmo, diante da insistência dos genitores, encaminhar por escrito, a decisão ao juiz competente. Neste contexto, conforme reportagem extraída do site Folha de S. Paulo, na internet (anexo 1) temos o exemplo de um jornalista chamado Bráulio de Souza, que ingressou com ação para mudar o nome para Claudio Lira de Souza, após campanha de conscientização contra a AIDS que intitulava o pênis (órgão reprodutor masculino) com seu nome Bráulio, o que causou grande desconforto e constrangimento. Para maior compreensão do assunto, segue abaixo uma relação de nomes vexatórios colhidos em registros cartoriais, que dariam causa a ação de modificação do prenome:

\begin{abstract}
Alce Barbuda, Amável Pinto, Asteróide Silverio, Cantinho da Vila Alencar da Corte Real Sampaio, Drágica Broko, Marciano Verdinho das Antenas Longas, Maria Passa Cantando, João Sem Sobrenome, Graciosa Rodela D'alho, Usnavy (em homenagem à U.S. Navy, a Marinha Americana), Chevrolet da Silva Ford, Holofontina Fufucas, Adolpho Hitler de Oliveira, Hypotenusa Pereira, dentre outros.
\end{abstract}

Demonstrada a grande imaginação de algumas pessoas em escolherem nomes exóticos para batizarem seus filhos, é importante reafirmar a necessidade de bom senso na hora de fazer o registro do nome, uma vez que o nome vexatório, ainda que passível de modificá-lo pode acarretar um grande sofrimento para seu possuidor.

Não há como definir de forma taxativa o que é vexatório ou não, pois assim como o juízo de valor, a definição é baseada em ponto de vista de cunho pessoal e o que é ridículo para uma pessoa, pode não ser para outra, deste modo, faz-se necessária a reafirmação da possibilidade de mutabilidade do prenome vexatório, afim de que a dignidade da pessoa humana prevaleça.

\title{
Apelidos Públicos e Notórios
}

É a hipótese de inserção de apelido notório pelo qual a pessoa se torna conhecida na sociedade ao nome. Trata-se de pseudônimo, que goza de toda proteção jurídica do nome, conforme prevê o artigo 58 da lei 6015/73.

\footnotetext{
${ }^{8}$ Art 55- Parágrafo único- lei 6015/1973. Os oficiais do registro civil não registrarão prenomes suscetíveis de expor ao ridículo os seus portadores. Quando os pais não se conformarem com a recusa do oficial, este submeterá por escrito o caso, independente da cobrança de quaisquer emolumentos, à decisão do Juiz competente.

610 Id on Line Rev. Mult. Psic. V.14, N. 49 p. 601-614, Fevereiro/2020 - ISSN 1981-1179 
Deste modo, temos os casos da apresentadora Maria da Graça Meneghel e do expresidente Luiz Inácio da Silva, que incluíram seus apelidos Xuxa e Lula, respectivamente, a seus nomes, passando a se chamarem Maria da Graça XUXA Meneghel e Luiz Inácio LULA da Silva.

Portanto, aquele que utiliza de apelido durante período consideravelmente longo, adquire o direito de retificar o registro civil para inclusão deste.

Dentro desta ótica de conhecimento público, não podemos ignorar os casos de mudança do nome em razão do transexualismo, que por se tratar de tema de grande relevância, falaremos em capítulo próprio.

\section{A Mudança do Prenome em razão do Transexualismo}

O princípio da dignidade da pessoa humana é soberano a qualquer outro tema que verse sobre o indivíduo em si.

O transexualismo é visto como uma questão psicológica em que um indivíduo se identifica por ser do sexo oposto, ainda que tenha todas as características físicas do sexo constante do seu registro de nascimento.

Deste modo, de acordo com Maria Helena Diniz " “o transexual é portador de desvio psicológico permanente de identidade sexual, com rejeição do fenótipo e tendência a automutilação ou auto-extermínio.”, ou seja, para o transexual masculino, seria este uma mulher que vive em um corpo de homem e para o transexual feminino, seria este um homem que vive em um corpo de mulher.

Se o transexualismo se dá em razão de questões psicológicas, a mudança do prenome deve ser respeitada para aquele que não se vê do sexo biológico, tendo em vista a incompatibilidade de uma pessoa que se sente mulher ser chamada por um nome masculino e vice-versa.

Desta forma, ainda que haja reafirmação da imutabilidade do nome civil, estando apenas alguns casos de sua modificação prevista em lei, o judiciário precisa evoluir conforme os costumes sociais, pois, se por um lado à lei autoriza a inclusão de apelido social ao nome, em razão do reconhecimento social que o indivíduo adquire através dele, o transexual, ainda que

9 DINIZ, Maria Helena. O estado atual do biodireito. 3. ed. São Paulo: Saraiva, 2006 - p. 966

Id on Line Rev. Mult. Psic. V.14, N. 49 p. 601-614, Fever
Edição eletrônica em http://idonline.emnuvens.com.br/id 
não tenha realizado cirurgia para mudança de sexo, que passa a ser socialmente conhecido pelo prenome ou apelido social, deve ter seu direito à modificação documental permitida, em razão da dignidade da pessoa humana ser indiscutivelmente absoluto.

Neste sentido, para maior esclarecimento, segue anexa a decisão sentença proferida pela $1^{\text {a }}$ Vara da Família de Florianópolis - Santa Catarina, pelo juiz de direito Luiz Cláudio Broering $^{10} \cdot .($ anexo 2$)$

Frente os novos tempos sociais, não há o que se falar em um judiciário retrógrado, pois a cada dia há o surgimento de novas situações que não estão previstas pela lei, porém, de suma importância para quem as vivencia, de modo que o acompanhamento jurídico deve estar em conformidade com o avanço social.

\section{Alteração do Prenome conforme a Legislação Aplicada}

Atualmente, o código civil versa no que se refere ao direito ao nome e a proteção legal da qual este goza.

Porém, o direito ao nome é complementado pela lei de registros públicos, nº 6015/1973, que trata da formalidade do ato de registro civil e dos direitos e deveres a ele relacionado.

O Registro Público, no Brasil possui três finalidades, sendo estas:

AUTENTICIDADE - é a qualidade do que é confirmado por ato de autoridade: de coisa, documento ou declaração verdadeiro;

SEGURANÇA - tendem a constituir malha firme e completa de informações, libertando-se dos riscos;

EFICÁCIA DOS ATOS REGISTRADOS - aptidão de produzir efeitos jurídicos, calcada na segurança dos assentos, na autenticidade dos negócios e declarações para eles transpostos.

O registro público gera efeitos a publicitários - como, por exemplo, interdição, uma vez que comumente é acessível ao conhecimento de todos, constitutivos - como, por exemplo, o registro de emancipação e casamentos e comprobatórios - como o assento de óbito de pessoa presumidamente morta.

${ }^{10}$ TJSC, Autos n 0037789-04.2012.8.24.0023, Juiz de Direito Luiz Cláudio Broering, j. 19/02/2015

612 Id on Line Rev. Mult. Psic. V.14, N. 49 p. 601-614, Fevereiro/2020 - ISSN 1981-1179

Edição eletrônica em http://idonline.emnuvens.com.br/id 
Diante das hipóteses de modificação do nome previstas em lei e do grande número de casos que surgem na intenção de fazê-lo, é contraditória a necessidade de movimentação da máquina judiciária para resolução de questões já previamente discutidas e definidas, causando congestionamento desnecessário da justiça brasileira.

Aquele que pretende alterar o nome, mesmo que em situação defendida pela lei, ainda passa por desgaste emocional e ainda, gastos financeiros, para poder exercer seu direito, ou não, uma vez que conforme diversas decisões judiciais, algumas pessoas possuem o pedido de alteração do nome negado.

Ora, se há expressa previsão legal do ato, sendo vedado o julgamento que contrarie a lei, não há o que se falar em necessidade de apreciação do poder judiciário no que se refere a mudança do nome civil, nos casos que estão amparados pela legislação, e ainda, uma facilitação para resolução dos casos que não estão previstos.

Cabe ressaltar que nesse quesito, deve haver respeito ao princípio da isonomia ${ }^{11}$, uma vez que todos são iguais perante a lei, pois, embora haja relativização da imutabilidade do prenome para casos específicos, todos aqueles que possuem casos passiveis de sua aplicabilidade, devem ser agraciados pelo deferimento de seus pedidos, respeitada a segurança jurídica de o fazer, uma vez que tal princípio deve ser considerado não somente ao fazer a lei, mas também ao aplica-la, não havendo qualquer discriminação.

\section{Considerações Finais}

Após breve análise de situações nas quais estão inseridas a mutabilidade do nome civil, há de se reafirmar a necessidade de adequação do judiciário com o avanço social, pois, a cada dia que se passa, surgem novas necessidades sociais, para as quais o judiciário deve estar preparado e desta maneira, solucionar os casos da melhor maneira possível.

Cabe ressaltar, a demonstração da necessidade de facilitação do processo de modificação do nome civil, baseando-se na lei e nos julgados existentes, pois, no que se refere à identidade e personalidade de uma pessoa, deve haver um maior cuidado para que a dignidade da pessoa humana seja sempre respeitada, e ainda, para que o judiciário não venha a ser congestionado com demandas que poderiam ser resolvidas de modo mais célere e menos

${ }^{11} \mathrm{https}: / /$ pt.wikipedia.org/wiki/Principio_da_igualdade

613 Id on Line Rev. Mult. Psic. V.14, N. 49 p. 601-614, Fevereiro/2020 - ISSN 1981-1179

Edição eletrônica em http://idonline.emnuvens.com.br/id 
burocrático, dando a vez para julgamentos de processos mais gravosos, embora não tenhamos a capacidade de analisar o que se diz mais importante para aqueles que buscam os meios judiciais.

O intuito do presente trabalho é a demonstração de uma amplificação da flexibilização do princípio da imutabilidade do nome civil, considerando os posicionamentos de julgados favoráveis ao tema, favorecendo a parte da sociedade que se inclui no problema, que não se demonstra pequena, não tão somente pelo processo, bem como pelo gasto financeiro daquele que busca satisfação do desejo de mudança do nome.

\section{Referências}

AMORIM, José Roberto Neves. Direito ao nome da pessoa física. São Paulo: Saraiva, 2003 - p.73.

DINIZ, Maria Helena. Curso de Direito - V. 5.18. ed. De acordo com o novo Código Civil. São Paulo: Saraiva, 2002

DINIZ, Maria Helena. O estado atual do biodireito. 3. ed. São Paulo: Saraiva, 2006 - p. 966

VENOSA, Silvio de Salvo, Direito Civil - 10ª Ed., São Paulo: Atlas, 2010.

VENOSA, Sílvio de Salvo- Direito civil: parte geral - 13. ed. - São Paulo: Atlas, 2013 - p. 202

Site www.recebiporemail.com.br acessado em: 15/05/2016

Site www.folha.uol.com.br acessado em 15/05/2016

WIKIPEDIA < disponível em www.wikipedia.com.br> acessado em : 12/05/2016.

\section{Como citar este artigo (Formato ABNT):}

GALVÃO, Natasha Santana Sloniewski. Relativização do Princípio da Imutabilidade do Nome Civil. Id on Line Rev.Mult. Psic., Fevereiro/2020, vol.14, n.49, p. 601-614. ISSN: 1981-1179.

Recebido: $17 / 02 / 2020$;

Aceito: 20/02/2020. 